\title{
Intranasal Administration of Oxytocin Attenuates Social Recognition Deficits and Increases Prefrontal Cortex Inhibitory Postsynaptic Currents following Traumatic Brain Injury
}

\author{
Avery Runyan,, ${ }^{1, *}$ Dana Lengel,, ${ }^{1, *}$ Jimmy W. Huh, ${ }^{3}$ - Jessica R. Barson,, ${ }^{1,2}$ and Ramesh Raghupathi ${ }^{1,2}$
}

https://doi.org/10.1523/ENEURO.0061-21.2021

${ }^{1}$ Program in Neuroscience, Graduate School of Biomedical Science and Professional Studies, Drexel University College of Medicine, Philadelphia, PA 19129, ${ }^{2}$ Department of Neurobiology and Anatomy, Drexel University College of Medicine, Philadelphia, PA 19129, and ${ }^{3}$ Department of Anesthesiology and Critical Care Medicine, Children's Hospital of Philadelphia, Philadelphia, PA 19104

\begin{abstract}
Pediatric traumatic brain injury (TBI) results in heightened risk for social deficits that can emerge during adolescence and adulthood. A moderate TBI in male and female rats on postnatal day 11 (equivalent to children below the age of 4) resulted in impairments in social novelty recognition, defined as the preference for interacting with a novel rat compared with a familiar rat, but not sociability, defined as the preference for interacting with a rat compared with an object in the three-chamber test when tested at four weeks (adolescence) and eight weeks (adulthood) postinjury. The deficits in social recognition were not accompanied by deficits in novel object recognition memory and were associated with a decrease in the frequency of spontaneous inhibitory postsynaptic currents (IPSCs) recorded from pyramidal neurons within Layer II/III of the medial prefrontal cortex (mPFC). Whereas TBI did not affect the expression of oxytocin (OXT) or the OXT receptor (OXTR) mRNAs in the hypothalamus and mPFC, respectively, intranasal administration of OXT before behavioral testing was found to reduce impairments in social novelty recognition and increase IPSC frequency in the MPFC in brain-injured animals. These results suggest that TBI-induced deficits in social behavior may be linked to increased excitability of neurons in the MPFC and suggests that the regulation of GABAergic neurotransmission in this region as a potential mechanism underlying these deficits.
\end{abstract}

Key words: excitability; GABAergic neurotransmission; intranasal administration; oxytocin; pediatric TBI; social behavior

\section{Significance Statement}

Traumatic brain injury (TBI) occurs in approximately half a million children below the age of 14 each year, with children younger than four years old at heightened risk. A younger age at injury is associated with worse behavioral and psychosocial outcomes in pediatric TBI patients, particularly as children age into adolescence and adulthood. In this study, we explored the role of oxytocin (OXT) in the long-term effects of pediatric TBI on social behaviors in adolescence and adulthood. The results indicate that intranasal administration of OXT improves social outcomes following pediatric TBI, potentially by increasing inhibitory neurotransmission within the medial prefrontal cortex (mPFC) and provide novel support for the use of intranasal OXT treatment to mitigate social deficits in pediatric TBI patients.

Received February 13, 2021; accepted May 14, 2021; First published May 25, 2021.

The authors declare no competing financial interests.
Author contributions: A.R., D.L., J.W.H., and R.R. designed research; A.R. and D.L. performed research; J.R.B. contributed unpublished reagents/ analytic tools; A.R., D.L., J.W.H., J.R.B., and R.R. analyzed data; A.R., D.L., J.W.H., J.R.B., and R.R. wrote the paper. 


\section{Introduction}

Nearly half a million children younger than 14 years old suffer from a traumatic brain injury (TBI) each year (Faul and Coronado, 2015). Pediatric TBI is associated with poor psychosocial outcomes in adolescence and young adulthood (Levin et al., 2004; Anderson et al., 2012; Rosema et al., 2012; Ryan et al., 2016), such as lower scores in communication, emotional perception, social skills, and fewer relationships (Ryan et al., 2014, 2016; Douglas, 2020). Chronic social and behavioral difficulties are the most prevalent and disabling outcome of pediatric TBI patients (Zamani et al., 2020), although these psychosocial deficits have historically received less attention in preclinical pediatric TBI studies.

A few preclinical studies to date have investigated social behavior as an outcome after pediatric TBI. Closed head injury in juvenile (21-d-old) mice led to impaired social recognition using the three-chamber test at four weeks postinjury (adolescence) and deficits in sociability at eight weeks following injury (adulthood; Semple et al., $2012,2017)$. Contusive brain trauma in neonate (14-dold) rats resulted in both sociability and social recognition deficits two weeks following injury (Wei et al., 2016). The mechanisms underlying these social deficits following pediatric TBI are not fully understood. TBI in $21-d-$-old mice resulted in diminished neuronal arbor complexity within the medial prefrontal cortex (mPFC) at eight weeks postinjury (Semple et al., 2017), a region that has been implicated in social processing in both rodents and humans (Ko, 2017).

Oxytocin (OXT), a neuropeptide known to affect PFC function and social behavior (Gimpl and Fahrenholz, 2001), is involved in social bonding and trust (Tops et al., 2013). Administration of OXT is reported to improve social recognition deficits in mouse models of autism (Andari et al., 2010; Sala et al., 2011; Hara et al., 2017). Transplantation of hypoxia-conditioned induced pluripotent stem cell-derived progenitor cells shortly after neonate TBI in rats improved sociability and social recognition, which was associated with an increase in both OXT and OXT receptor (OXTR) levels in the injured cortex (Wei et al., 2016).

The majority of central nervous system OXT is produced within the paraventricular nucleus (PVN) in the hypothalamus (Knobloch et al., 2012), from which OXT producing neurons project to various brain regions including the mPFC (Bakos et al., 2018; Jurek and Neumann, 2018). Neuronally expressed OXTRs are G-protein-coupled receptors which are typically coupled to

This work weas supported in part by the National Institutes of Health Grant R01 NS110898 (to J.W.H. and R.R.) and Commonwealth Universal Research Enhancement from the Pennsylvania Department of Health Grants SAP 410007-9710 (to R.R.) and SAP 410-007-7079 (R.R.).

${ }^{*} A . R$. and D.L. contributed equally to this work.

Correspondence should be addressed to Ramesh Raghupathi at rr79@ drexel.edu.

https://doi.org/10.1523/ENEURO.0061-21.2021

Copyright $@ 2021$ Runyan et al.

This is an open-access article distributed under the terms of the Creative Commons Attribution 4.0 International license, which permits unrestricted use, distribution and reproduction in any medium provided that the original work is properly attributed.
$\mathrm{G}_{\alpha \mathrm{q}}$ and activate downstream signaling pathways involving protein kinase C (Bakos et al., 2018). Within the mPFC, OXTRs are predominantly expressed on inhibitory somatostatin (SOM) neurons and have been implicated in the modulation of social behaviors (Nakajima et al., 2014). OXT has been found to increase spontaneous inhibitory postsynaptic currents (IPSCs) and the release of GABA (Wrobel et al., 2010; Harden and Frazier, 2016). We previously demonstrated that TBI in 11-d-old rats results in an increase in spontaneous EPSCs and a concomitant decrease in spontaneous IPSCs in Layer II/III pyramidal neurons within the mPFC (Lengel et al., 2020). Increasing excitatory currents in the PFC decreases social exploration in rodents (Yizhar et al., 2011; Bicks et al., 2015), suggesting that changes in excitation/inhibition balance within the medial PFC may be a mechanism underlying deficits in social behaviors following TBI.

The purpose of the current study was to define the extent of social behavior deficits following a moderate closed-head injury in the 11-d-old rat and to determine whether OXT treatment would reverse these deficits. To investigate whether the behavioral effects of OXT may be facilitated by its actions within the medial PFC, we measured the effects of bath application of OXT on electrophysiological properties of medial PFC pyramidal neurons using whole-cell patch clamp recordings.

\section{Materials and Methods}

\section{Animals}

All animal procedures were performed in accordance with the regulations of the Institutional Animal Care and Use Committee and followed the National Institutes of Health Guide for the Care and Use of Laboratory Animals. Timed-pregnant [embryonic day (E)20] female Sprague Dawley rats were purchased from Charles River Laboratories and gave birth in the animal facility (average litter size was between 11 and 13 pups). A caveat to the present study is that the stress of transportation may affect social behavior in the offspring. Animals were housed under a normal 12/12 h light/dark cycle (lights on from 7 A.M. to 7 P.M.) with ad libitum access to standard rat chow and water. Age-matched male and female rats used as the familiar and novel rats in the three-chamber test were also purchased from Charles River and housed in the same room under the same conditions as the test subjects. The pups were weaned on postnatal day 21 and group housed under the same conditions. Animals were handled for 5$10 \mathrm{~min}$ at least two to three times per week before the start of behavioral assessment.

\section{TBI}

The model of moderate pediatric TBI used in this study was originally characterized by Raghupathi and Huh (2007) and was subsequently used in multiple studies (Hanlon et al., 2017, 2019; Lengel et al., 2020). Animals from each litter were randomly assigned to sham-injury or brain-injury groups. Sham $(n=52)$ or brain injury $(n=60)$ was administered on postnatal day 11 , the neurologic 
equivalent of a child below the age of 4 (Porterfield, 1994; Yager and Thornhill, 1997; Rice and Barone, 2000). Male and female rat pups were anesthetized using isoflurane (Patterson Veterinary, 5\% induction, 2-3\% maintenance) and an incision was made to expose the skull. Animals were then placed in a plastic rodent restrainer (Braintree Scientific Braintree MA) and moved onto the stage of an electronic controlled cortical impact (eCCl) device (Custom Design International, Richmond VA). The impactor tip was driven into the intact skull at a velocity of $5 \mathrm{~m} / \mathrm{s}$ (3-mm distance from zero point, 100-ms dwell time) over the left lateral hemisphere midway between the bregma and lambda. After impact, the pup was placed in a supine position and the time until the pup righted itself onto all four paws was measured. After righting, pups were then placed back on isoflurane and examined for hematoma and skull fractures, and the incision was sutured closed. Sham-injured animals were surgically prepared but did not receive an impact. The total time under anesthesia for brain-injured and sham-injured animals did not exceed $10 \mathrm{~min}$. Animals were placed in a separate cage to recover and were subsequently returned to the dam. Surgical procedures and recovery were performed on a heating pad to maintain the body temperature at $37^{\circ} \mathrm{C}$.

\section{Behavioral testing}

All behavioral tests were conducted in the dark under red light with the three-chamber test being done first at four or eight weeks postinjury, followed by novel object recognition memory test, and assessment of locomotor activity (week 5 for the OXT treatment arm of the study). All behaviors were recorded and testing and scoring from videos were performed by an evaluator who was blinded to the injury and treatment status of the animals.

\section{Three-chamber test}

Social behavior was quantified using a three-chamber test. Rats were tested four or eight weeks after injury. The three-chamber apparatus was custom made, comprised of three chambers with two Plexiglas dividers with a $10-\mathrm{cm}$ opening to allow the rat to move between the two far chambers $(40 \times 40 \mathrm{~cm})$ and a middle chamber $(20 \times 40 \mathrm{~cm})$. A camera equipped with an infrared detector was used to record the behavior of the test rat in each of the stages, from which the time spent sniffing the rat/cup (stage 2), or the novel/familiar rat (stage 3), was determined. In the first stage, the rat was habituated to the three-chamber apparatus in the dark for $5 \mathrm{~min}$, following which it was herded into the middle chamber and the Plexiglas doors were lowered to keep the animal in the middle chamber. In preparation for stage 2, an age-matched and sex-matched rat that the test rat had never seen before was put in an inverted wire mesh cup ( $14 \mathrm{~cm}$ in diameter, $20 \mathrm{~cm}$ in height) in one of the outer chambers and an identical empty cup was placed in the opposite chamber. Stage 2, which measures sociability, began once the Plexiglas doors were raised. This stage lasted $10 \mathrm{~min}$, and the number of seconds the test rat spent sniffing the "rat cup" and "empty cup" was counted. At the end of this stage, the lights were turned on and the test rat was again herded back into the middle chamber and the Plexiglas doors closed. Another new novel rat was placed in the empty cup. In stage 3 , social recognition was measured as the time the test rat spent sniffing the "familiar rat" (from stage 2) and the "novel rat" over 10 min. The discrimination index (DI) in stage 2 used the equation [(time sniffing rat cup) - (time sniffing empty cup)]/[(time sniffing rat cup) + (time sniffing empty cup)] and, for stage 3 , the equation [(time sniffing novel rat) (time sniffing familiar rat)]/[(time sniffing novel rat) + (time sniffing familiar rat)].

\section{Novel object recognition}

To assess non-social memory, a novel object recognition paradigm was used. All testing and habituation occurred in the dark and the behaviors were recorded using a camera equipped with an infrared detector. Rats were first habituated over $2 \mathrm{~d}$ to a plastic box $(61 \times 41 \mathrm{~cm})$ for $10 \mathrm{~min}$ each day. On the third day, rats began the novel object recognition test by being familiarized with two identical objects placed in opposite corners of the box for $5 \mathrm{~min}$. Rats were returned to their home cage, then returned $1 \mathrm{~h}$ later to the box with one of the objects switched for a new ("novel") object. The time the rat sniffed the "familiar" object versus the novel object was determined. DI was calculated using the following equation: [(time sniffing novel object) - (time sniffing familiar object)]/[(time sniffing novel object) + (time sniffing familiar object)].

\section{Locomotor activity}

To assess any motor deficits, rats were tested individually in $43.2 \times 43.2 \mathrm{~cm}$ activity monitor boxes (Activity Monitor version 5, Med Associates) during a 30-min period. The total distance traveled, as tracked by the number of beam breaks, was measured and averaged in 5min bins for each animal.

\section{Quantitative real-time PCR}

At the conclusion of behavioral testing in adolescence (five weeks postinjury), tissue from the PVN and PFC regions of a subset of rats (11 sham, 13 injured) were dissected after decapitation of male and female rats for quantitative real-time PCR (qRT-PCR). For dissection of the PVN, coronal slices were obtained between -1.2 and $-2.2 \mathrm{~mm}$ from bregma. For dissection of the PFC, coronal slices were obtained between +3.0 and +4.0 from bregma. The PVN was dissected as a reversed isosceles triangle, $1.0 \mathrm{~mm}$ bilateral to the third ventricle and between the fornix structures. The PFC was dissected in a diamond shape, bilateral from the dorsomedial tip of the slice to the corpus callosum, and then along the border of the corpus callosum to its ventral tip. Tissue was then stored in RNA Later (QIAGEN Inc.) at $-20^{\circ} \mathrm{C}$ until further processing. The RNA from the tissue was extracted using a RNeasy Mini kit (QIAGEN Inc.) along with DNase 1 (QIAGEN Inc.). RNA yields were measured with a NanoDrop Lite spectrophotometer (Thermo Electron North America LLC) and resulted in $A_{260} / A_{280}$ ratios of 2.0-2.1, indicating high purity. RNA was 


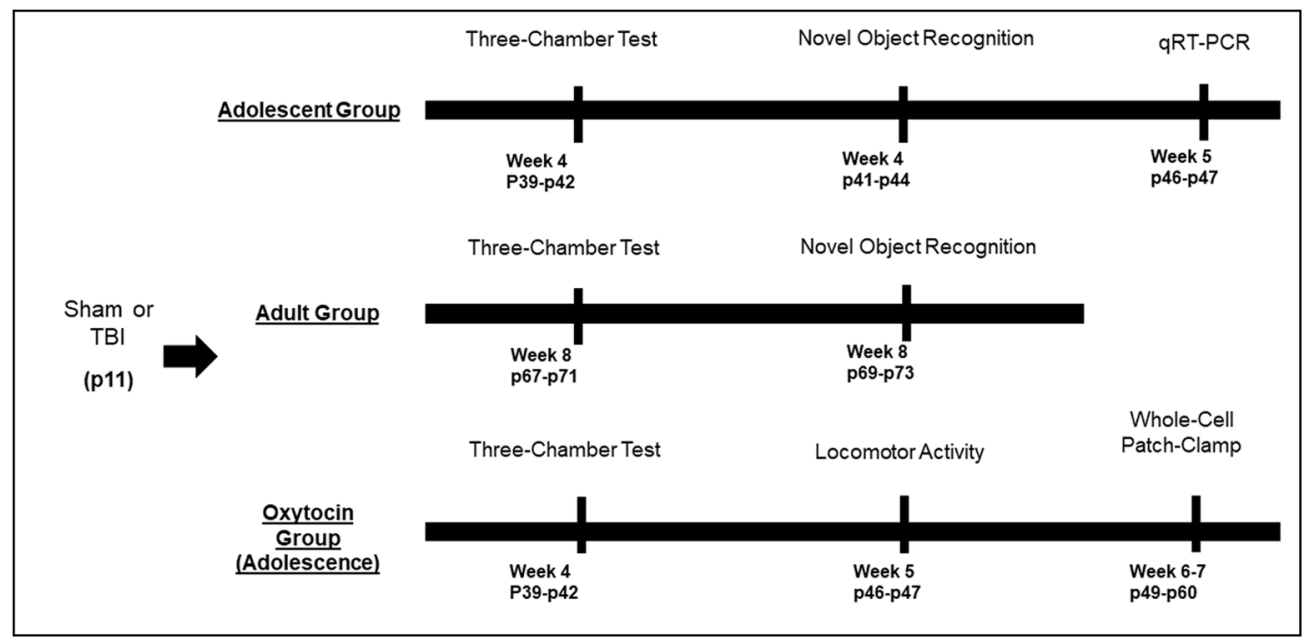

Figure 1. Timeline of experiments. Eleven-day-old rat pups were subjected to TB1 or sham injury. Behavioral experiments were conducted in three separate cohorts of animals beginning at either four weeks postinjury (adolescent group and OXT group) or eight weeks postinjury (adult group). At the conclusion of the behavioral testing in adolescence, animals were used to generate tissue for qRT-PCR experiments, and animals from the OXT group were used for electrophysiological experiments.

converted to cDNA using SuperScript VILO Master Mix (Invitrogen) in a SimpliAmp Thermal Cycler (Applied Biosystems). Triplicate samples of cDNA, SYBR Green PCR reagent (Applied Biosystems), and target primer or cyclophilin primer were run on 96-Well MicroAmp Fast Optical Reaction Plates (Applied Biosystems). The protocol was set to be $2 \mathrm{~min}$ at $50^{\circ} \mathrm{C}, 10 \mathrm{~min}$ at $95^{\circ} \mathrm{C}, 40$ cycles of $15 \mathrm{~s}$ at $95^{\circ} \mathrm{C}$, and $1 \mathrm{~min}$ at $60^{\circ} \mathrm{C}$. Primers were designed with the help of the NCBI Primer design tool (http://www. ncbi.nlm.nih.gov/tools/primer-blast/) and purchased from Invitrogen at ThermoFisher Scientific. Serial dilutions of primers were tested for specificity and efficiency on sham tissue of the respective regions. Only primers with one peak in the melt curve indicating good specificity were used. Efficiency was determined by serial dilutions of primers and graphing log of the dilutions against the threshold cycle $(\mathrm{Ct})$ values. Target mRNA expression was quantified relative to cyclophilin-A using the relative quantification method $\left(\Delta \Delta \mathrm{C}_{\mathrm{T}}\right)$, which was quantified using the following equation: -2 (Average CT values of target gene-Average CT values of Cyclophilin-A). We chose to use cyclophilin-A as a reference gene in this study because it was reported to be a stable housekeeping gene in multiple brain injury paradigms (Langnaese et al., 2008; Swijsen et al., 2012; TimaruKast et al., 2015). The sequences for the primers were as follows: cyclophilin-A (cyc; $200 \mathrm{nM}$ ), forward: 5'-GTGTTC TTCGACATCACGGCT-3' and reverse: 5'-CTGTCTT GGAACTITGTCTGCA-3'; OXT (200 nM), forward: 5'-AT CTGCTGTAGCCCGGATGG-3' and reverse: 5'-GAAGG AAGCGCCCTAAAGGT-3'; OXTR (100 nm), forward: 5'-G GGCCACCACAACGCAACGAG-3' and reverse: 5'-AGACC GCCCAGCAATCGAAG-3'.

\section{Intranasal OXT administration}

The following intranasal administration protocol was adapted from (Brabazon et al., 2017) and (Meidahl et al., 2018). Six days before any behavioral intranasal OXT testing, rats began a protocol to familiarize them to receiving intranasal drops. On the first day, rats were placed into a DecapiCone disposable rodent restrainer (Braintree Scientific) with the end sealed off but which allowed the rat to move relatively freely in the bag for $10 \mathrm{~min}$. The next day, the rats were restrained in the nose cone and flipped on their back for $1 \mathrm{~min}$. From the third to fifth day approximately three drops of saline were intranasally given to each rat. To administer drops, rats were restrained in the DecapiCone and flipped on their back. Drops of $6 \mu \mathrm{l}$ of saline were pipetted using a micropipette into each naris. After the last drop, rats remained on their back for another minute to ensure the saline or OXT did not drip out. Animals that sneezed out all the drops were given additional drops to better acclimate them. On the day of testing, rats were given OXT (O4375, Sigma-Aldrich) or saline $1 \mathrm{~h}$ before testing. Sham-injured and brain-injured rats were randomly assigned to receive either 20 or $60 \mu \mathrm{g}$ of OXT (Hara et al., 2017; Meidahl et al., 2018) or saline.

\section{Slice preparation}

All patch clamp recordings were done at the conclusion of behavioral testing in adolescence (Fig. 1). Rats were anesthetized with Euthasol $(100 \mathrm{mg} / \mathrm{kg}$, Patterson Veterinary) and then transcardially perfused with $60 \mathrm{ml}$ of oxygenated slicing artificial CSF (aCSF) containing $34 \mathrm{~mm}$ sucrose, $11 \mathrm{~mm}$ glucose, $24 \mathrm{~mm} \mathrm{NaHCO}_{3}, 2.5 \mathrm{~mm}$ $\mathrm{KCl}, 1.25 \mathrm{~mm} \mathrm{NaH} \mathrm{PO}_{4}, 10 \mathrm{~mm} \mathrm{MgSO}$, and $0.5 \mathrm{~mm}$ $\mathrm{CaCl}_{2}$ at $\mathrm{pH}$ 7.4. Brains were quickly removed and glued to the slicing stage of a vibrating microtome (Leica Microsystems), and $300 \mu \mathrm{m}$ coronal slices containing the $\mathrm{mPFC}$ were cut between 3 and $4 \mathrm{~mm}$ anterior to bregma. Slices were incubated for $1 \mathrm{~h}$ at $37^{\circ} \mathrm{C}$ in oxygenated aCSF containing $126 \mathrm{~mm} \mathrm{NaCl}, 10 \mathrm{~mm}$ glucose, $26 \mathrm{~mm} \mathrm{NaHCO}$, $2.5 \mathrm{~mm} \mathrm{KCl}, 1.25 \mathrm{~mm} \mathrm{NaH}_{2} \mathrm{PO}_{4}, 1 \mathrm{~mm}$ $\mathrm{MgSO}_{4}$, and $2 \mathrm{mM} \mathrm{CaCl}_{2}$ at $\mathrm{pH}$ 7.4. After incubation, the 
slices were allowed to equilibrate at room temperature for at least $1 \mathrm{~h}$ before recording.

\section{Whole-cell patch clamp electrophysiology}

Brain slices containing the medial PFC were individually transferred to a recording chamber and continually perfused with oxygenated aCSF maintained at $34^{\circ} \mathrm{C}$. In a subset of recordings, OXT was added to the bath solution at a $1 \mu \mathrm{m}$ concentration, as previously used (Harony-Nicolas et al., 2017). OXT was bathed onto a slice for $10 \mathrm{~min}$ before the beginning of recording and was maintained for the duration of recording (three to five cells per slice). Using an Olympus BX51WI microscope and Samsung SCB-2001 camera, individual Layer II/III pyramidal neurons were identified with infrared differential interference contrast imaging. Borosilicate glass patch pipettes were pulled to a resistance of 5-8 $\mathrm{M} \Omega$ and filled with $128 \mathrm{~mm} \mathrm{~K}$ gluconate, $10 \mathrm{~mm}$ HEPES, $0.05 \mathrm{~mm} \mathrm{CaCl}_{2}$, $0.3 \mathrm{~mm}$ GTP, 5 mм ATP, 1 $\mathrm{mm}$ glucose, and $4 \mathrm{~mm} \mathrm{NaCl}$ at $\mathrm{pH} 7.4$ for whole-cell patchclamp recordings of intrinsic excitability measures and for a subset of recordings of excitatory and inhibitory currents ( $n=18$ sham cells and 23 injured cells). Additional wholecell patch-clamp recordings of excitatory and inhibitory currents ( $n=14$ sham cells and 21 injured cells) were obtained using an intracellular solution was used consisting of the following: $110 \mathrm{~mm}$ Cs-Gluconate, $10 \mathrm{~mm} \mathrm{CsCl,} 1 \mathrm{~mm}$ EGTA, $1 \mathrm{~mm} \mathrm{CaCl}_{2}$, $10 \mathrm{~mm}$ HEPES, and $1 \mathrm{~mm}$ HEPES, and adjusted to $\mathrm{pH}$ 7.3. Whole-cell recordings were acquired using an axon MultiClamp 700A amplifier and PClamp 9.2 data acquisition software (Molecular Devices), digitized using a DigiData 1332A digitizer (Molecular Devices) at $10 \mathrm{kHz}$, and low-pass filtered at $1 \mathrm{kHz}$. The access resistance was continuously monitored during recordings, and the recording was stopped if it exceeded $25 \mathrm{M} \Omega$. A. Only neurons with a membrane potential of at least $-60 \mathrm{mV}$ and an action potential (AP) overshoot $>0 \mathrm{mV}$ were used in the analysis. If a neuron exhibited a non-accommodating, high-frequency spiking pattern in response to depolarizing current injections, it was deemed a fast-spiking interneuron and was excluded from further analysis. In voltage clamp mode, neurons were held at $-70 \mathrm{mV}$ to record spontaneous EPSCs for $5 \mathrm{~min}$, and then at $0 \mathrm{mV}$ to record spontaneous IPSCs, the reversal potentials for chloride ions and cations, respectively.

\section{Measurement of intrinsic excitability and synaptic properties}

The data were analyzed using ClampFit 10.5 (Molecular Devices). The resting membrane potential was measured as the average voltage immediately after whole-cell configuration was achieved. The input resistance, rheobase, AP threshold, and AP amplitude were measured from current clamp recordings, which consisted of a series of depolarizing current steps (duration $=1 \mathrm{~s}$ ) from -100 to $220 \mathrm{pA}$ in $20-\mathrm{pA}$ increments. Input resistance was determined from voltage responses to the first four hyperpolarizing steps $(-100$ to $-80 \mathrm{pA})$. The rheobase current was determined as the minimal current needed to induce an AP. The AP threshold was measured as the voltage at the onset of an AP. The AP amplitude was measured as the difference between the threshold and the peak of an AP. In voltage clamp traces the spontaneous EPSCs and spontaneous IPSCs were analyzed using an automated template-matching protocol. The mean spontaneous current frequency was calculated for each cell across the full duration of the recording.

\section{Statistical analysis}

Statistical analyses were performed using Statistica version 7.0 (StatSoft). All datasets were confirmed to contain a normal distribution and homogenous variances, as indicated by a Shapiro-Wilk and Levene's test, respectively. An independent samples t test was used for comparisons between two means. For comparisons between more than two means, an ANOVA was used. Post hoc tests, when necessary were conducted using the Neuman-Keuls correction; $p<0.05$ was considered significant. Kolmogorov-Smirnov statistical analysis was used to quantify differences among distributions (cumulative probability plots), in which case a $p<0.005$ was accepted as significant.

\section{Results}

\section{Acute response to injury}

All brain-injured animals exhibited a skull fracture and hematoma immediately following injury on postnatal day 11 (data not shown). Brain-injured animals exhibited an increase in the time to right themselves following the impact (injury; $F_{(1,108)}=57, p=0.000$, ANOVA; Table 1), which did not differ between male and female rats (sex: $F_{(1,108)}=$ $0.0005, p=0.98$, ANOVA). Brain injury also caused a brief period of apnea which did not differ between male and female rats (sex: $t_{(108)}=0.14, p=0.88$, unpaired $t$ test). The latency of the righting reflex was similar in animals receiving saline, $20 \mu \mathrm{g}$ OXT, and $60 \mu \mathrm{g}$ OXT, confirming the randomization of animals to treatment groups (Table 1; treatment: $F_{(2,39)}=0.19, p=0.82$, ANOVA).

\section{Effects of pediatric TBI on social behaviors during adolescence}

Brain injury on postnatal day 11 did not result in impairments in sociability (stage 2) in adolescence (Fig. 2A,C). Both sham-injured and brain-injured animals spent significantly more time interacting with the rat cup compared with an empty cup, as measured by total sniffing time $\left(F_{(1,58)}=191.8, p=0.00\right.$, ANOVA; Fig. $\left.2 A\right)$. The discrimination ratio during stage 2 was slightly but significantly higher in brain-injured rats compared with their shaminjured counterparts $\left(F_{(1,29)}=4.6, p=0.04\right.$, ANOVA; Fig. $\left.2 C\right)$ although the total time spent sniffing both stimuli during stage 2 did not differ between sham and injured rats (data not shown; $F_{(1,29)}=0.18, p=0.6$, ANOVA). Brain-injured animals exhibited an impairment in social novelty recognition (stage 3) during adolescence (Fig. 2B,D). Statistical analysis of sniffing time during stage 3 revealed a significant interaction between injury status and stimulus (novel vs familiar; $F_{(1,58)}=6.3, p=0.01$; Fig. 2B). Post hoc tests showed that sham-injured animals spent significantly more time sniffing 
Table 1: Acute neurologic status of rats in the study

\begin{tabular}{|c|c|c|c|c|}
\hline Outcome & Group & $N$ & Righting reflex (s) & Apnea (s) \\
\hline \multirow[t]{4}{*}{ Behavior (adolescence) } & Sham & 16 & $69 \pm 9$ & NA \\
\hline & Injured & 20 & $284 \pm 40^{\star}$ & $10 \pm 2$ \\
\hline & Behavior sham & 12 & $70 \pm 11$ & NA \\
\hline & (Adult) injured & 12 & $151 \pm 16^{\star}$ & $13 \pm 1$ \\
\hline \multirow[t]{6}{*}{ Behavior (OXT) } & Sham + saline & 9 & $97 \pm 24$ & NA \\
\hline & Sham + OXT 1X & 7 & $119 \pm 22$ & NA \\
\hline & Sham + OXT $3 x$ & 8 & $79 \pm 15$ & NA \\
\hline & Injured + saline & 10 & $301 \pm 32^{*}$ & $5 \pm 1$ \\
\hline & Injured + OXT $1 \times$ & 7 & $306 \pm 99^{*}$ & $6 \pm 3$ \\
\hline & Injured + OXT $3 \times$ & 10 & $320 \pm 50^{*}$ & $16 \pm 4^{*}$ \\
\hline
\end{tabular}

Eleven-day-old male and female rat pups were randomly assigned to either sham-injured or brain-injured groups. Sham-injured and brain-injured rats were randomly assigned to receive intranasal administration of $20 \mu \mathrm{g}(1 \times)$ or $60 \mu \mathrm{g}(3 \times)$ OXT. Subsets of the animals tested in the behavioral assays were randomly assigned to be euthanized for mRNA measurements and whole-cell patch clamp electrophysiology. Latency to regain righting reflex and times of apnea were recorded as described in Materials and Methods; ${ }^{*} p<0.05$ compared with sham-injured rats.

the novel rat compared with the familiar rat $(p=0.005)$ and compared with their brain-injured counterparts $(p=0.02)$. In contrast, brain-injured rats did not exhibit a significant difference in the time sniffing a novel rat compared with a familiar rat $(p=0.6)$. Statistical analysis also revealed that the DI during stage 3 was significantly lower in brain-injured animals compared with sham-injured animals $\left(F_{(1,29)}=4.75, p=0.03\right.$, ANOVA; Fig. 2D). The total time spent sniffing both stimuli during stage 3 did not differ between sham and injured rats (data not shown; $F_{(1,29)}=2.4, p=0.12$, ANOVA). Overall, these experiments demonstrate that brain-injured male and female rats exhibit impairments in social recognition but intact sociability at four weeks postinjury.

\section{Effects of pediatric TBI on social behaviors during adulthood}

Brain injury on postnatal day 11 did not result in impairments in sociability (stage 2) in adulthood (Fig. $3 A, C$ ). Both sham-injured and brain-injured animals spent significantly more time interacting with the rat cup compared with an empty cup, as measured by total sniffing time $\left(F_{(1,32)}=140.5, p=0.00\right.$; Fig. $\left.3 A\right)$. The discrimination ratio during stage 2 was not significantly different between sham-injured and brain-injured rats $\left(F_{(1,16)}=0.1, p=0.7\right.$, ANOVA; Fig. 3C). The total time spent sniffing both stimuli during stage 2 also did not differ between sham and injured rats (data not shown; $F_{(1,16)}=0.5, p=0.4$, ANOVA). Brain-injured animals exhibited an impairment in social novelty recognition (stage 3 ) during adulthood (Fig. 3B,D). Statistical analysis revealed a significant interaction effect of injury status and the type of stimulus on total sniffing time $\left(F_{(1,32)}=4.1, p=0.04 ;\right.$ Fig. 3B). Post hoc tests showed that sham-injured animals spent significantly more time sniffing the novel rat compared with the familiar rat $(p=0.02)$, whereas brain-injured rats did not exhibit a significant difference in the time sniffing a novel rat compared with a familiar rat $(p=0.5)$. Statistical analysis also revealed that the DI during stage 3 was significantly lower in brain-injured animals compared with sham-injured animals $\left(F_{(1,16)}=4.6, p=0.04\right.$, ANOVA; Fig. 3D). The total time spent sniffing both stimuli during stage 3 was slightly but significantly higher in brain-injured rats compared with sham-injured rats (data not shown; $F_{(1,16)}=5.6, p=0.03$, ANOVA). Overall, these experiments demonstrate that brain-injured male and female rats exhibit impairments in social recognition but intact sociability at eight weeks postinjury.

\section{Novel object recognition during adolescence and adulthood}

Brain injury did not result in an impairment in novel object recognition memory during either adolescence (Fig. $4 A$ ) or adulthood (Fig. 4B). Statistical analysis revealed no significant effect of injury status on the DI at either four weeks postinjury $\left(F_{(1,29)}=0.63, p=0.43\right.$, ANOVA) or eight weeks postinjury $\left(F_{(1,9)}=0.22, p=0.65\right.$, ANOVA). The sex of the animal did not have a significant effect on the DI at either four weeks postinjury $\left(F_{(1,29)}=0.19, p=0.66\right.$, ANOVA) or eight weeks postinjury $\left(F_{(1,9)}=0.06, p=0.81\right.$, ANOVA). Thus, these experiments confirm that TBI did not impair novel object recognition memory at either four or eight weeks postinjury.

\section{Expression of mRNA for OXT and OXTRs}

To determine whether TBI induces changes in the OXT system, we measured OXT and OXTR mRNA within the PVN and PFC, respectively (Fig. 5A,B). Statistical analysis revealed no significant effects of injury $\left(F_{(1,19)}=0.25\right.$, $p=0.62$, ANOVA) or $\operatorname{sex}\left(F_{(1,19)}=0.04, p=0.83\right)$ on OXT mRNA within the PVN (Fig. $5 A$ ). Similarly, there was no significant effect of injury $\left(F_{(1,20)}=2.11, p=0.16\right.$, ANOVA) or $\operatorname{sex}\left(F_{(1,20)}=0.22, p=0.64\right.$, ANOVA) on OXTR mRNA within the PFC (Fig. 5B). Thus, TBI did not induce changes in OXT expression within the PVN or in OXTR expression within the PFC.

\section{Effects of OXT treatment on social behaviors and novel object recognition following TBI}

To determine whether OXT treatment affects social behaviors after TBI, OXT (20 or $60 \mu \mathrm{g}$ ) was intranasally administered $1 \mathrm{hr}$ before testing in the three-chamber test (Fig. 6). OXT treatment did not have a significant effect on sniffing times during stage 2 (sociability; Fig. 6A). Overall, rats spent more time sniffing the rat cup compared with the empty cup $\left(F_{(1,82)}=360.8, p=0.00\right.$, ANOVA), regardless of injury status $\left(F_{(1,82)}=0.3, p=0.5\right.$, ANOVA) or 

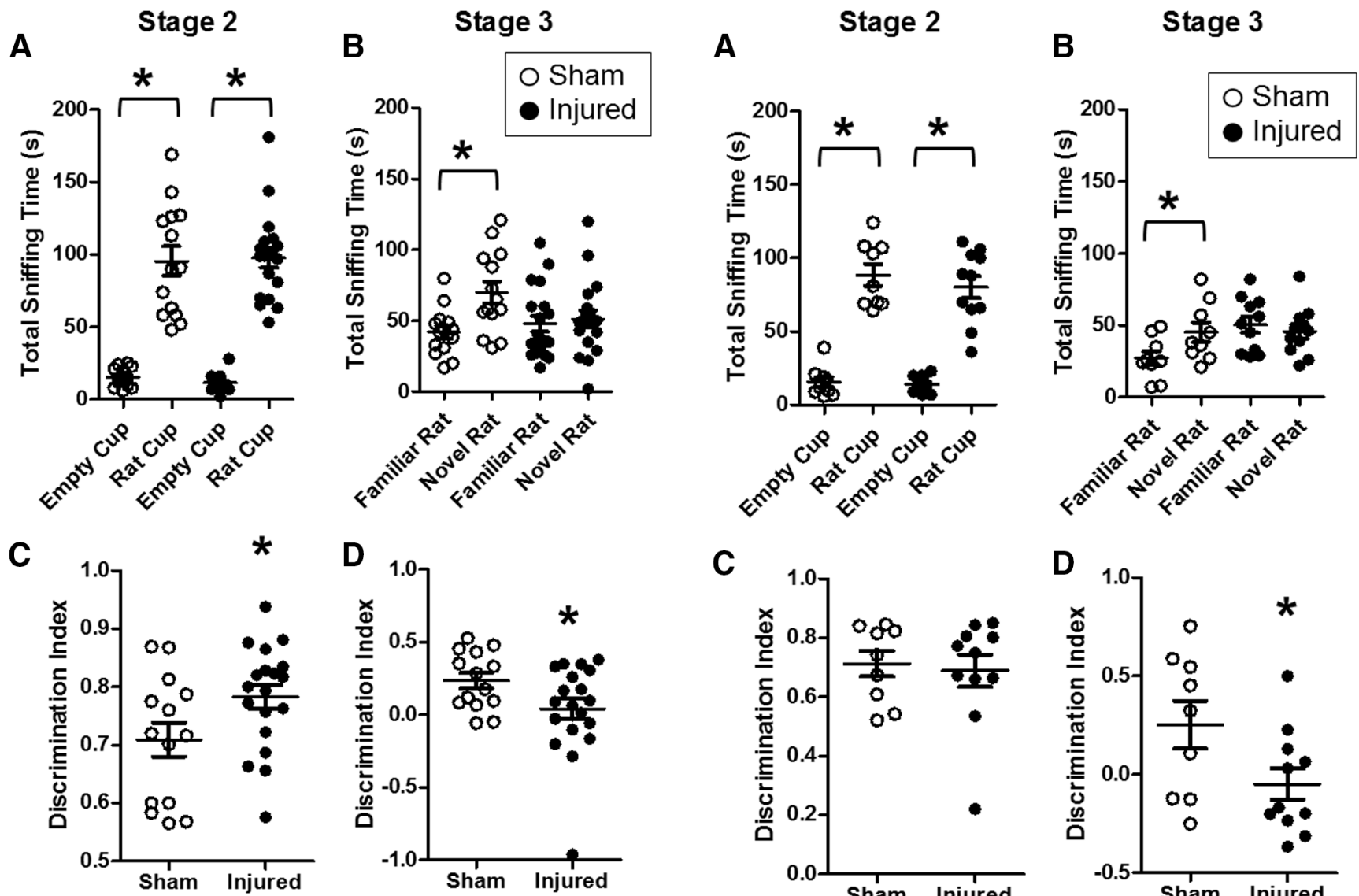

Figure 2. Pediatric TB1 impaired social recognition but not sociability during adolescence. Eleven-day-old male and female rat pups were tested for sociability (stage $2 ; \boldsymbol{A}, \boldsymbol{C}$ ) and social recognition (stage 3; $\boldsymbol{B}, \boldsymbol{D}$ ) at four weeks after injury (adolescent age) using the three-chamber test as described in Materials and Methods. Data are presented as time (in seconds) spent interacting with rat/ object $(\boldsymbol{A}, \boldsymbol{B})$ or as $\mathrm{DI}(\boldsymbol{C}, \boldsymbol{D})$. Open symbols represent sham animals, closed symbols represent injured animals. Bars represent group mean values, and the error bars represent SEM; ${ }^{*} p<0.05$.

treatment $\left(F_{(2,82)}=0.9, p=0.4\right.$, ANOVA $)$. Interestingly, there was a significant effect of OXT treatment on the DI during stage $2\left(F_{(2,41)}=4.1, p=0.02\right.$; Fig. $\left.6 C\right)$. Post hoc tests revelated that the $\mathrm{DI}$ was significantly lower in animals treated with $60 \mu \mathrm{g}$ OXT compared with both saline $(p=0.02)$ and $20 \mu \mathrm{g}$ OXT $(p=0.04)$, although these animals still spent more time sniffing the rat cup compared with the empty cup (Fig. 6A), indicating intact sociability. OXT treatment dose dependently increased social recognition (stage 3) in brain-injured animals (Fig. 6B,D). Statistical analysis of the DI scores revealed a significant interaction between injury status and treatment $\left(F_{(2,38)}=\right.$ 3.6, $p=0.03$; Fig. $6 D$ ). Post hoc tests indicated that treatment with $60 \mu \mathrm{g}$ OXT significantly increased the DI in brain-injured rats compared with brain-injured rats receiving either saline $(p=0.00)$ or $20 \mu \mathrm{g}$ OXT $(p=0.02)$. OXT did not affect the total sniffing time during stage 3 (data not shown; $\left.F_{(2,38)}=2.2, p=0.1\right)$. OXT treatment did not affect novel object recognition memory (data not shown). Overall, these experiments demonstrate that OXT dose dependently increased social recognition in brain-injured
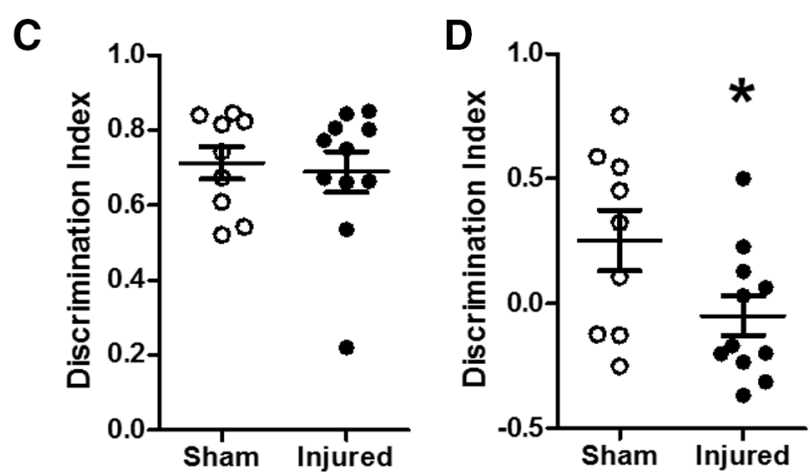

Figure 3. Pediatric TB1 impaired social recognition but not sociability during adulthood. Eleven-day-old male and female rat pups were tested for sociability (stage $2 ; \boldsymbol{A}, \boldsymbol{C}$ ) and social recognition (stage $3 ; \boldsymbol{B}, \boldsymbol{D}$ ) at eight weeks after injury (adult age) using the three-chamber test as described in Materials and Methods. Data are presented as time (in seconds) spent interacting with rat/object $(\boldsymbol{A}, \boldsymbol{B})$ or as DI $(\boldsymbol{C}, \boldsymbol{D})$. Open symbols represent sham animals, closed symbols represent injured animals. Bars represent group mean values, and the error bars represent SEM; ${ }^{*} p<0.05$.

animals without affecting non-social memory, with the higher $60 \mu \mathrm{g}$ dose having the greatest effect on social recognition memory.

\section{Effects of OXT on novelty-induced locomotor activity}

An ANOVA with repeated measured revealed that there was no significant effect of brain injury on the distance traveled during a $30-\mathrm{min}$ period $\left(F_{(1,30)}=0.09, p=0.75\right.$; Fig. 7).

Treatment with $60 \mu \mathrm{g}$ OXT $1 \mathrm{hr}$ before locomotor testing also did not affect the distance traveled during the 30-min pe$\operatorname{riod}\left(F_{(1,30)}=0.4, p=0.5\right.$, ANOVA). There was a main effect of time on the distance traveled $\left(F_{(5,150)}=257.7, p=0.000\right.$, repeated measures ANOVA), with all animals exhibiting more activity during the first $5 \mathrm{~min}$ compared with the other time points $(p<0.001)$, confirming the assessment of novelty-induced activity. Thus, these experiments confirm that neither TBI nor OXT treatment affected novelty-induced locomotor activity. 
A

Adolescence

B

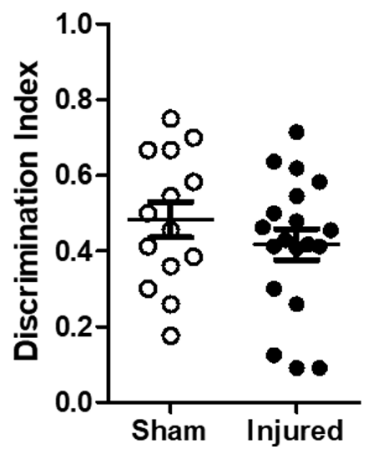

Adulthood

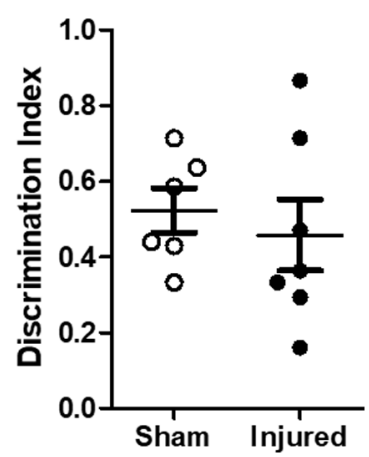

Figure 4. Brain-injured animals did not exhibit impairments in novel object recognition memory. At fourweeks (adolescence, $\boldsymbol{A}$ ) and eight weeks (adulthood, $\boldsymbol{B}$ ) following injury, sham-injured and braininjured animals were tested for novel object recognition memory as described in Materials and Methods. The DI was calculated as described in Materials and Methods. Open symbols represent sham animals, closed symbols represent injured animals. Bars represent group mean values, and the error bars represent SEM.

\section{Whole-cell patch clamp electrophysiology}

\section{Intrinsic excitability of Layer II/III neurons}

Current clamp recordings from pyramidal cells within the mPFC from sham and brain-injured animals (illustrated in Fig. $8 A$ ) reveled a significant effect of TBI on input resistance $\left(F_{(1,35)}=4.6, p=0.03\right.$, ANOVA; Fig. $\left.8 D\right)$. The input resistance was significantly higher in neurons from brain-injured animals compared to their sham-injured counterparts $(p=0.03)$ and was not affected by $\operatorname{OXT}\left(F_{(1,35)}=0.3, p=0.6\right.$, ANOVA $)$. An increase in input resistance is typically associated with an increase in neuronal excitability. There was also a significant effect of TBI on the rheobase $\left(F_{(1,36)}=9.7, p=0.003\right.$, ANOVA; Fig. $8 A, C)$, which was significantly decreased in neurons from brain-injured animals compared to sham

A

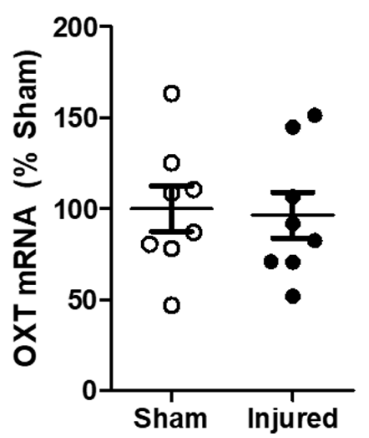

B

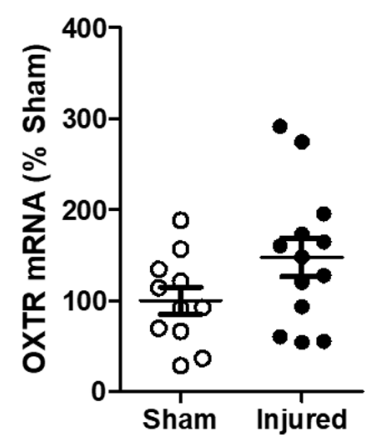

Figure 5. Expression of mRNA for OXT and OXTR in adolescence was not affected following TB1 in 11-d-old rats. After behavioral testing at four to five weeks postinjury, a subset of animals was euthanized and the expression of OXT $(\boldsymbol{A})$ and OXTR $(\boldsymbol{B})$ was evaluated in the PVN and mPFC, respectively. Open symbols represent sham animals, closed symbols represent injured animals. Expression (ddCT) values were normalized to sham values. Bars represent group mean values, and the error bars represent SEM.

animals $(p=0.003)$, indicative of increased excitability, and was similarly not affected by OXT $\left(F_{(1,36)}=0.01, p=\right.$ 0.9 , ANOVA). However, there was no difference in the spike frequency in response to varying levels of current injection between the groups $\left(F_{(2,27)}=0.7, p=0.53\right.$, repeated measures ANOVA; Fig. $8 B$ ). There were no differences between cells recorded from sham and braininjured animals in the membrane voltage $\left(F_{(1,35)}=0.97\right.$, $p=0.3$, ANOVA; Fig. $8 E)$, spike threshold $\left(F_{(1,37)}=0.1 .5\right.$, $p=0.2$, ANOVA; Fig. $8 F)$, or spike amplitude $\left(F_{(1,37)}=\right.$ $3.0, p=0.09$, ANOVA; data not shown). Overall, these experiments indicate that TBI resulted in an increase in the excitability of Layer II/III pyramidal cells within the mPFC which was not affected by OXT.

\section{Excitatory inputs to Layer II/III neurons}

Representative traces of spontaneous EPSCs are illustrated in Figure $9 A$. There were no significant differences in either the frequency $\left(F_{(1,58)}=3.1, p=0.08\right.$, ANOVA; Fig. $9 B)$ or amplitude $\left(F_{(1,60)}=2.3, p=0.1\right.$, ANOVA; Fig. $\left.9 C\right)$ of spontaneous EPSCs between sham-injured cells and brain-injured cells recorded with either aCSF or OXT. Thus, there were no significant effects of either TBI or OXT application on excitatory inputs to Layer II/III neurons.

\section{Inhibitory inputs to Layer II/III neurons}

Representative traces of spontaneous IPSCs are illustrated in Figure 10A. There was a significant interaction effect on the frequency of spontaneous IPSCs (status $x$ treatment: $F_{(1,49)}=5.6, p=0.02$, ANOVA). Post hoc tests revealed that IPSC frequency was significantly lower in cells from brain-injured animals recorded with ACSF relative to cells from sham-injured animals $(p=0.008)$ and cells from brain-injured animals recorded in the presence of OXT ( $p=0.02$; Fig. 10B). There was no difference in the IPSC frequency in sham cells bathed with either aCSF or OXT $(p=0.49)$. However, there were no effects of TBI $\left(F_{(1,49)}=1.3, p=0.25\right.$, ANOVA $)$ or OXT $\left(F_{(1,49)}=0.0006\right.$, $p=0.98$, ANOVA) on the amplitude of spontaneous IPSCs (Fig. 10C). There were no effects of sex on the frequency $\left(F_{(1,49)}=0.64, p=0.4\right.$, ANOVA $)$ or amplitude $\left(F_{(1,49)}=2.7\right.$, $p=0.1$, ANOVA) of IPSCs recorded from Layer II/III.

Because IPSCs evoked by SOM-expressing interneurons, which typically project to distal dendrites of pyramidal neurons (Urban-Ciecko and Barth, 2016), are smaller compared with parvalbumin-expressing interneurons (Holley et al., 2019), cumulative probability analyses on the amplitudes and frequencies of either small $(<20 \mathrm{pA})$ or large $(<60 \mathrm{pA})$ IPSCs were performed. A KolmogorovSmirnov test revealed a significant difference in the distribution of frequencies of both small IPSCs $\left(D_{(43)}=0.67\right.$, $p<0.001)$ and large IPSCs $\left(\mathrm{D}_{(572)}=0.33, p<0.001\right)$ between sham and injured mPFC cells bathed with aCSF (Fig. 10D-G). Bath application of OXT led to a rightward shift in the distribution of frequencies of both small IPSCs $\left(D_{(140)}=0.37, p<0.005\right)$ and large IPSCs $\left(D_{(428)}=0.27\right.$, $p<0.001$ ) in brain-injured cells (Fig. 10E,G) but did not affect either small IPSCs $\left(D_{(204)}=0.33, p>0.1\right)$ or large IPSCs $\left(D_{(744)}=0.06, p>0.1\right)$ in sham cells (Fig. 10D,F). There was no effect of TBI on the amplitude of either small 


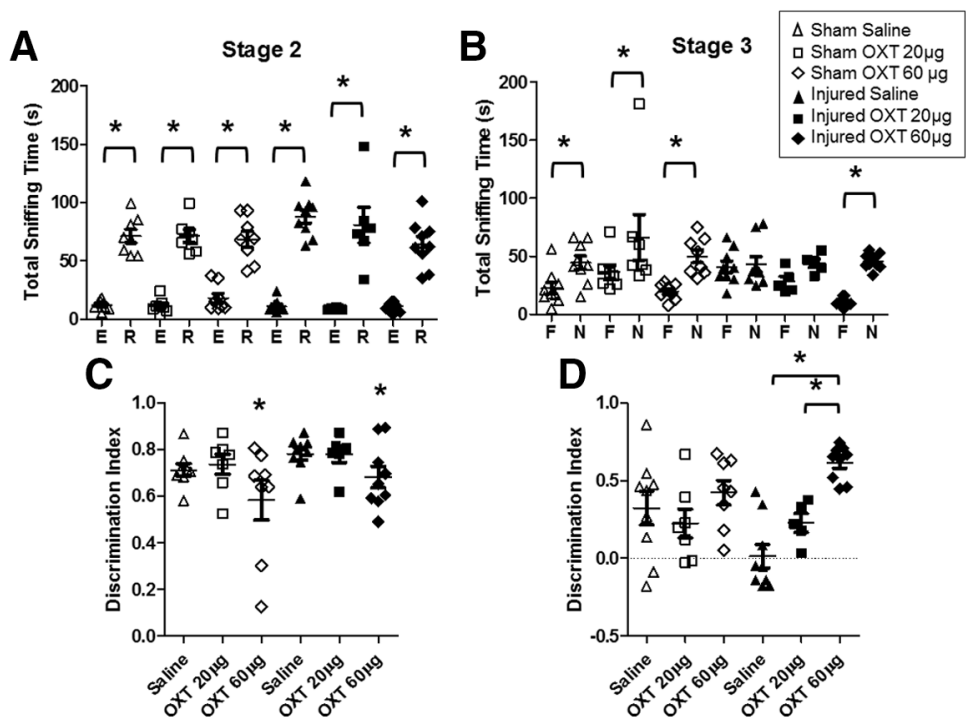

Figure 6. Intranasal administration of OXT administration reversed social recognition deficits in brain-injured animals in adolescence. At $1 \mathrm{hr}$ before testing animals in the three-chamber test at four after injury, sham-injured and brain-injured animals were administered with saline, OXT at $20 \mu \mathrm{g}$, or oxy at $60 \mu \mathrm{g}$ as described in Materials and Methods. A, Seconds sniffing in stage 2. $\boldsymbol{B}$, Seconds sniffing in stage 3. C, DI in stage 2. D, DI in stage 3. E, empty cup; R, rat cup; F, familiar rat; N, novel rat. Open symbols represent sham rats, filled symbols represent injured rats, triangles represent vehicle-treated, squares represent 20 - $\mu$ g oxy-treated rats, diamonds represent $60-\mu \mathrm{g}$ oxy-treated rats; ${ }^{\star} p<0.05$ in all panels. In panel $\boldsymbol{C},{ }^{\star} p<0.05$ compared with brain-injured animals that received saline. Horizontal lines represent group mean values, and the error bars represent SEM.

IPSCs $\left(\mathrm{D}_{(75)}=0.27, p>0.1\right)$ or large IPSCs $\left(\mathrm{D}_{(349)}=0.08\right.$, $p>0.1$ ) in cells bathed with aCSF, although bath application of OXT led to a leftward shift in the distribution of amplitudes of small IPSCs in brain-injured cells $\left(D_{(205)}=0.36\right.$, $p<0.001$; Fig. 10/), without affecting large IPSC amplitudes $\left(D_{(436)}=0.13, p>0.1\right.$; Fig. 10K). Moreover, OXT did not affect the amplitudes of either small IPSCs $\left(D_{(236)}=\right.$ $0.22, p>0.1)$ or large IPSCs $\left(\mathrm{D}_{(1150)}=0.05, p>0.1\right)$ in sham cells (Fig. 10H,J).

Overall, these experiments indicate that TBI resulted in a significant decrease in the frequency of IPSCs recorded from Layer II/III pyramidal neurons within the MPFC, and that bath-application of OXT increased the IPSC frequency in pyramidal cells from brain-injured animals without having an overall effect on IPSC amplitude. Moreover, OXT

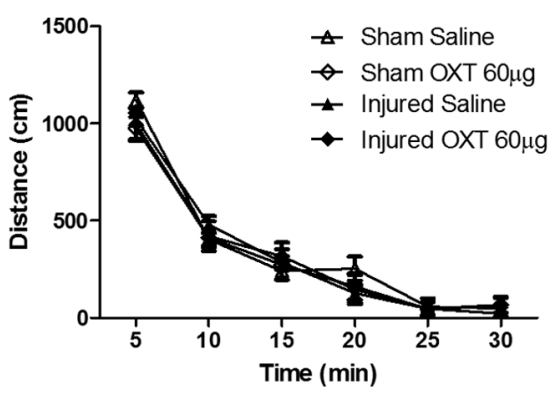

Figure 7. OXT administration did not affect novelty-induced locomotor activity. At five weeks after brain injury and following testing in the three-chamber test, sham-injured and brain-injured animals were tested for locomotor activity. Animals were administered either saline or OXT $60 \mu \mathrm{g}$ as described in Materials and Methods. increased the frequency of IPSCs of both small and large amplitudes but had a selective effect on the amplitudes of small IPSCs in mPFC neurons from brain-injured animals.

\section{Discussion}

The present study demonstrates that moderate TBI in the 11-d-old rat resulted in social recognition deficits at four and eight weeks postinjury, corresponding to adolescence and adulthood, respectively. Intranasal administration of OXT before behavioral testing reversed social recognition deficits in brain-injured animals. Closed-head injury did not affect sociability in the three-chamber test or novel object recognition memory, indicating that these deficits were specific to the neural circuits underlying social memory rather than recognition memory in general. Moreover, brain-injured animals exhibited a significant increase in excitability and decrease in the frequency of spontaneous IPSCs in Layer II/III PFC pyramidal neurons within the $\mathrm{mPFC}$, which was consistent with previous results (Lengel et al., 2020) Bath application of OXT increased IPSC frequency but did not affect neuronal excitability. Overall, these findings suggest that OXT improves social recognition memory following pediatric $\mathrm{TBI}$, and that this effect may be mediated by the facilitation of inhibitory neurotransmission within the PFC by OXT.

The findings from this study differ from previous studies demonstrating changes in social behaviors following pediatric TBI. Semple et al. (2012) found that contusive brain trauma in 21-d-old mice resulted in deficits in sociability and preference for social novelty during adulthood (p60p70), but not adolescence (p35-p42). Another study reported deficits in both sociability and social novelty preference during adolescence (p31) following $\mathrm{CCl}$ in 14- 


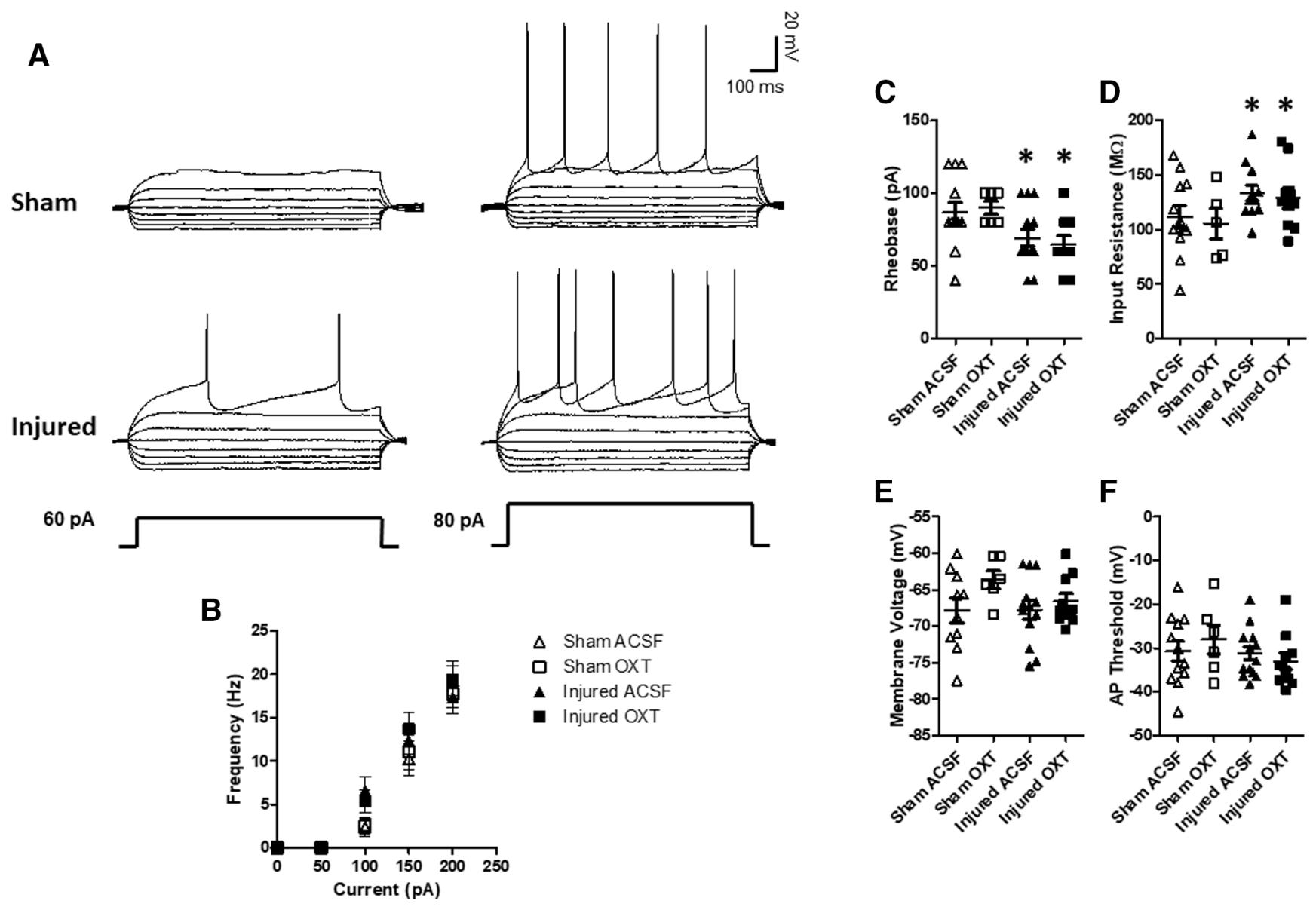

Figure 8. OXT did not affect membrane properties of Layer II/III pyramidal neurons within the mPFC. Following behavioral testing, slices containing the mPFC were obtained at six to seven weeks after injury and neuronal activity was measured using whole-cell patch clamp electrophysiology as described in Materials and Methods. $\boldsymbol{A}$, Representative current clamp traces from sham and brain-injured neurons. $\boldsymbol{B}$, Frequency of neuron firing in response to varying levels of current injection. $\boldsymbol{C}$, Rheobase. $\boldsymbol{D}$, Input resistance. $\boldsymbol{E}$, Membrane voltage. $\boldsymbol{F}$, Spike threshold. Bars represent mean group values, and error bars represent SEM. Open triangles represent sham cells bathed with aCSF $(N=12)$, open squares represent sham cells bathed with $1 \mu \mathrm{M}$ OXT $(N=6)$, filled triangles represent injured cells bathed with aCSF $(N=13)$, and filled squares represent injured cells bathed with $\mathrm{OXT}(N=10) ;{ }^{*} p<0.05$.

d-old rats (Wei et al., 2016). These seemingly inconsistent results are likely because of a variety of factors including age at time of injury, injury model, and species. While we did not observe sex differences in the effects of TBI on social behaviors, Semple et al. (2017) found that while male mice injured on postnatal day 21 exhibited deficits in both sociability and preference for social novelty in adulthood, female mice exhibited reduced sociability but intact preference for social novelty. Moreover, these sex-dependent changes were associated with a reduction in dendritic complexity within the PFC and hippocampus that was more apparent in males and preceded the onset of social impairments (Semple et al., 2017). Although evidence of neuronal death or neurodegeneration within the mPFC, has not been observed (Lengel et al., 2020), changes in dendritic morphology following TBI may be a potential mechanism underlying changes in the excitatory/inhibitory balance within the mPFC.

Our results demonstrate that OXT improves social recognition following TBI, which corroborate previous evidence that improvements in social behaviors mediated by stem cell transplantation following $\mathrm{CCl}$ are associated with higher levels of OXT and OXTR (Wei et al., 2016). The lack of an effect of OXT on social behaviors in sham animals in the current study supports previous findings in which OXT did not affect social novelty in wild-type mice and only increased preference for social novelty in mice that exhibit autism-like behaviors (Zhang et al., 2016; Hara et al., 2017). The ability of OXT to improve social recognition in brain-injured animals may be related to its ability to regulate GABAergic activity. TBI resulted in a reduction in the frequency but not amplitude of spontaneous IPSCs in the mPFC, which could implicate presynaptic changes in inhibitory neurotransmission. An imbalance of the cortical excitation/inhibition balance has been previously implicated in adult TBI (Witgen et al., 2005; Bonislawski et al., 2007; Ding et al., 2011; Cantu et al., 2015; Carron et al., 2016; Brizuela et al., 2017; Witkowski et al., 2019) and has been linked to reductions in inhibitory neurotransmission (Witgen et al., 2005; Bonislawski et al., 2007; Cantu et al., 2015; Carron et al., 2016). OXTRs within the PFC are expressed on regular-spiking SOM 
A

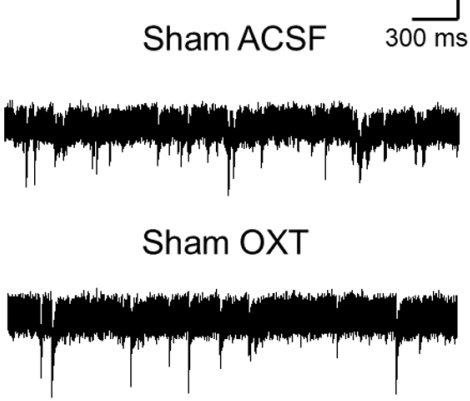

Injured ACSF

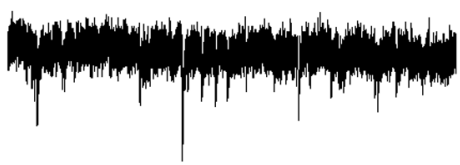

Injured OXT

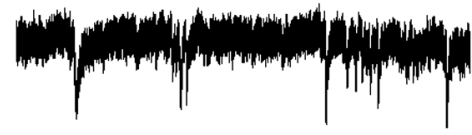

B

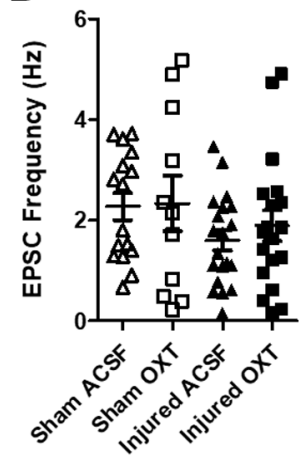

C

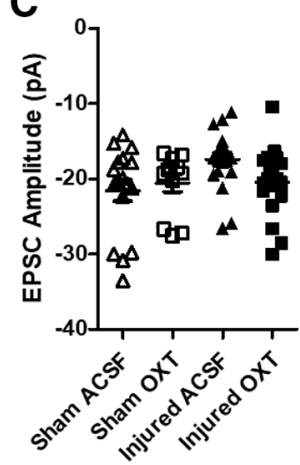

Figure 9. OXT did not affect spontaneous EPSCs in Layer II/III neurons within the mPFC. $\boldsymbol{A}$, Representative traces of spontaneous EPSCs recorded from Layer II/III pyramidal neurons within the mPFC. $\boldsymbol{B}$, Frequency of spontaneous EPSCs. $\boldsymbol{C}$, Amplitude of spontaneous EPSCs. Bars represent group mean value, and error bars represent SEM. Open triangles represent sham cells bathed with aCSF $(N=16)$, open squares represent sham cells bathed with $1 \mu \mathrm{M}$ OXT $(N=11)$, filled triangles represent injured cells bathed with aCSF $(N=20)$, filled squares represent injured cells bathed with $1 \mu \mathrm{m}$ OXT $(N=19)$.

neurons (Nakajima et al., 2014), which synapse with pyramidal neurons in Layer II/III (Urban-Ciecko and Barth, 2016). Although reductions in the numbers of SOM-containing inhibitory interneurons have been reported following moderate TBI in adult rats (Carron et al., 2020), a previous study reported that pediatric TBI does not result in neuron loss in the mPFC (Lengel et al., 2020).

Bath application of OXT in the present study was found to increase the IPSC frequency but not amplitude in brain-injured PFC slices, suggesting that the effect of OXT on IPSCs were likely mediated through the regulation of GABA release from inhibitory interneurons synapsing with pyramidal neurons, rather than acting directly on OXTRs on pyramidal neurons. These effects of OXT were specifically observed in pyramidal neurons from brain-injured but not sham slices. Although the effects of OXT on IPSC frequency in PFC pyramidal neurons have not previously been investigated, a previous study reported an increase in IPSC frequency recorded from mossy cells in the dentate gyrus with application of the OXTR agonist, TGOT (Harden and Frazier, 2016). In part, this differential response to TGOT may reflect its higher specificity for the OXTR over the vasopressin (AVP) receptor compared with

OXT (Harden and Frazier, 2016). This observation also suggests that OXTRs in the mPFC may be exhibit higher sensitivity for OXT following TBI, possibly because of a decrease in basal OXT levels, resulting in greater OXTR activation by exogenous OXT in injured cells relative to sham cells.

Because OXTRs are predominantly expressed on SOM neurons in the mPFC (Nakajima et al., 2014), which evoke smaller IPSCs in pyramidal neurons compared with parvalbumin neurons (Holley et al., 2019), we predicted that OXT would preferentially affect the frequency and/or amplitude of small IPSCs. While OXT significantly increased the frequency of both small and large IPSCs in injured cells, it selectively affected the amplitudes of small IPSCs resulting in a leftward shift in the distribution of small IPSC amplitudes recorded from injured cells, suggestive of an increase in the number of smaller currents relative to larger currents. The beneficial effects of OXT on social recognition may therefore be a result of increasing GABAergic release from terminals of GABAergic neurons, including SOM and likely parvalbumin interneurons as well. Thus, although beyond the scope of this study, measuring the direct effects of OXT bath application on the activity of SOM and parvalbumin interneurons following TBI will be an important area of future investigation.

In contrast to a previous study (Lengel et al., 2020), we did not observe changes in spontaneous EPSC frequency in Layer II/III pyramidal neurons in the mPFC. This may be because of differences in the timing of electrophysiological recordings, which were conducted at the conclusion of behavioral testing (between six and seven weeks postinjury) in the current study. However, we did observe an increase in neuronal excitability (increase in input resistance and decrease in rheobase) and a reduction in spontaneous IPSC frequency, corroborating our previous findings and suggesting the effects of TBI on Layer II/III EPSCs may be transient. In contrast, our current data indicate that the effects of TBI on Layer II/III IPSCs are sustained up to seven weeks following injury. We previously identified changes in the excitatory amino acid transporter 3 (EAAT3) and voltage-gated sodium channel $\beta 3$-subunit $(\mathrm{NaV} \beta 3)$ as potential mechanisms underlying the effects on cellular function by progesterone treatment during the first week following injury (Lengel et al., 2020). In the present study, because the OXT was administered $1 \mathrm{hr}$ before behavioral testing, it is more likely that its effects were mediated through acute changes in signal transduction, rather than transcriptional changes or anti-inflammatory effects of OXT. Furthermore, whereas progesterone was found to predominantly affect neuronal excitability and excitatory neurotransmission, the findings from this study suggest that the behavioral effects of OXT may be specifically mediated through its effects on inhibitory neurotransmission (Harden and Frazier, 2016).

We did not observe changes in OXT mRNA in the PVN or OXTR mRNA in the PFC. Although expression of OXT and OXTR proteins were not measured in the current study, a previous study reported no changes in OXT or OXTR protein concentrations at two weeks following TBI in 14-d-old rats (Wei et al., 2016). Nonetheless, TBI may 
A

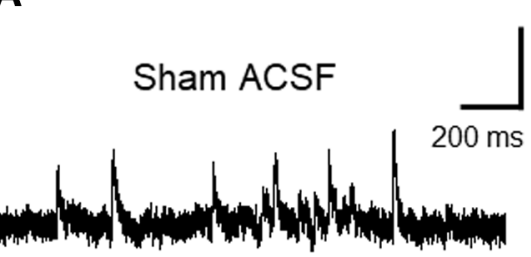

Sham OXT

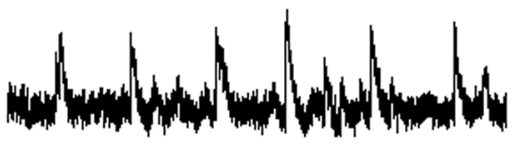

Injured ACSF

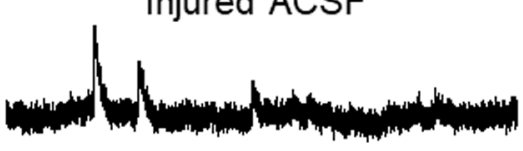

Injured OXT

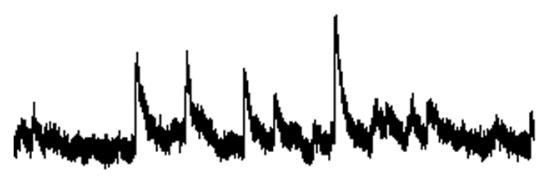

D Sham (small $<20 \mathrm{pA})$

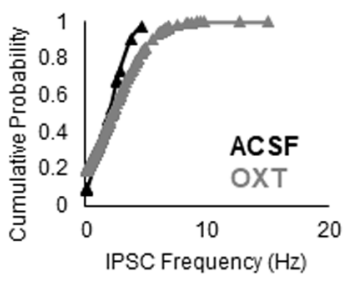

F Sham (large $>60 \mathrm{pA})$

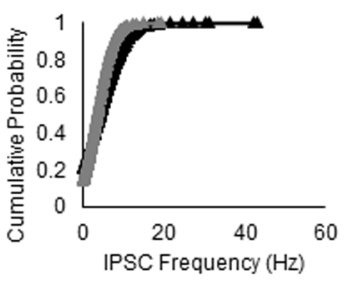

H Sham (small $<20 \mathrm{pA}$ )
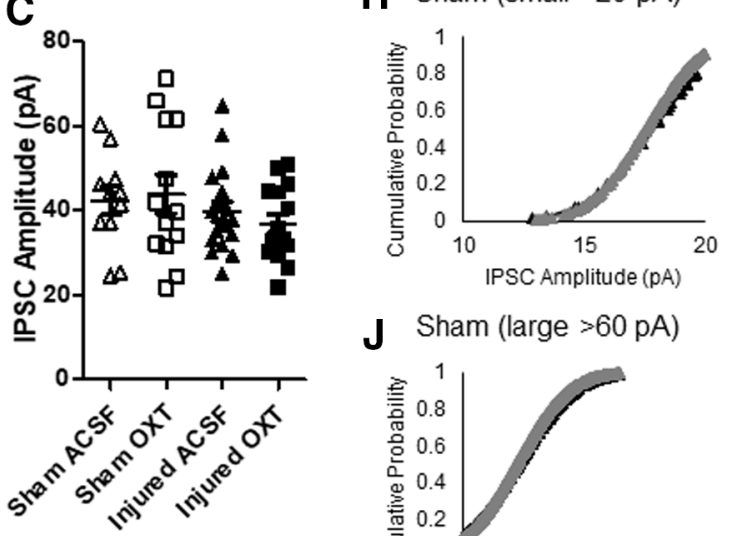

J Sham (large $>60 \mathrm{pA}$ )
E Injured (small $<20 \mathrm{pA}$ )

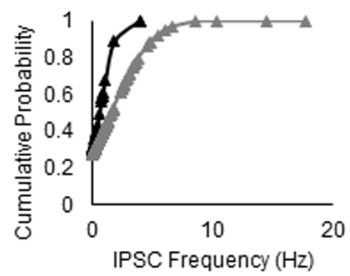

G Injured (large $>60 \mathrm{pA})$

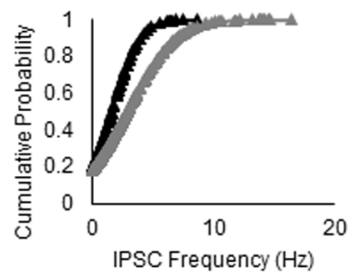

I Injured (small $<20 \mathrm{pA}$ )
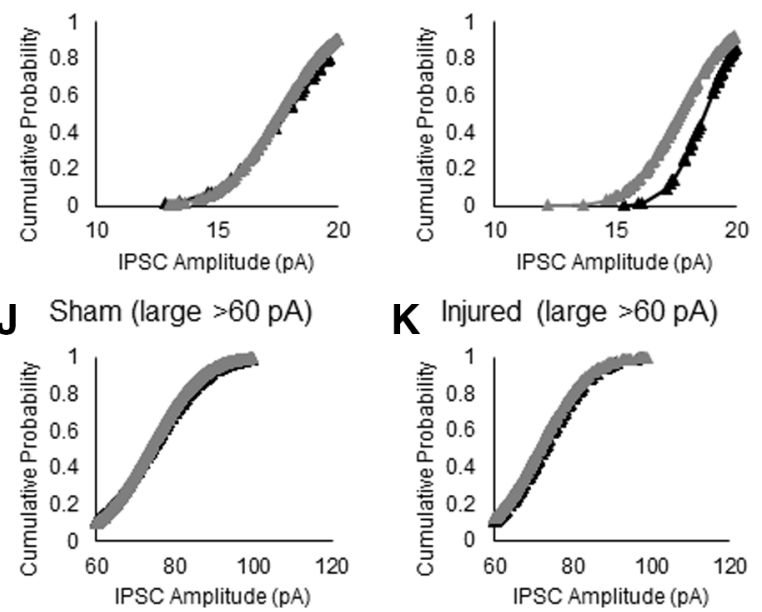

K Injured (large $>60 \mathrm{pA})$

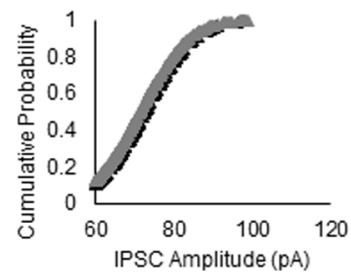

Figure 10. OXT increased the frequency of spontaneous IPSCs in Layer II/III neurons within the mPFC. $\boldsymbol{A}$, Representative traces of spontaneous IPSCs recorded from Layer II/III pyramidal neurons within the mPFC. $\boldsymbol{B}$, Frequency of spontaneous IPSCs. $\boldsymbol{C}$, Amplitude of spontaneous IPSCs. Bars represent group mean value, and error bars represent SEM. Cumulative probability of small IPSC frequencies in sham $(\boldsymbol{D})$ and injured cells $(\boldsymbol{E}) . \boldsymbol{F}, \boldsymbol{G}$, Cumulative probability of large IPSC frequencies in sham $(\boldsymbol{F})$ and injured cells $(\boldsymbol{G})$. Cumulative probability of small IPSC amplitudes in sham $(\boldsymbol{H})$ and injured cells $(\boldsymbol{I})$. Cumulative probability of large IPSC amplitudes in sham $(\boldsymbol{J})$ and injured cells $(\boldsymbol{K}$; Ryan et al., 2016; Douglas, 2020). Open triangles represent sham cells bathed with aCSF $(N=13)$, open squares represent sham cells bathed with $1 \mu \mathrm{M}$ OXT $(N=12)$, filled triangles represent injured cells bathed with aCSF $(N=17)$, filled squares represent injured cells bathed with $1 \mu \mathrm{M}$ OXT $(N=15) ;{ }^{*} p<0.05$.

influence important developmental processes that occur during the first postnatal weeks. Notably, the maturation of OXT-producing neurons in the rat hypothalamus occurs later compared with other neuropeptides including AVP and SOM, with OXT mRNA levels reaching about half of the adult levels during the third postnatal week (Almazan et al., 1989). Moreover, this upregulation in gene expression occurs concomitantly with the establishment of synaptic input to the PVN and the development of output projections from the PVN to target regions during the first two postnatal weeks (Almazan et al., 1989). Thus, it is possible that TBI leads to a loss of PVN projections to the mPFC, resulting in a reduction in OXT release in the mPFC and, in turn, a decrease in the basal activation of OXTRs on these neurons. A loss of basal OXT transmission in the mPFC could also explain the selective effect of
OXT administration in injured but not in sham cells, where there may be higher levels of endogenous OXT release.

Although changes in OXT or OXTR mRNA were not observed at six weeks after injury, we cannot rule out the possibility of transient changes in TBI-induced expression of these genes at earlier time-points following injury. The hallmark of pediatric TBI is diffuse (traumatic) axonal injury (Kannan et al., 2014) which has been validated in our model (Raghupathi and Huh, 2007). Moreover, although histopathological damage within the MPFC following pediatric TBI has not been observed (Lengel et al., 2020), it is possible that the PVN OXT neurons that project to the mPFC may be injured, resulting in impaired transmission of OXT to the MPFC and/or other areas involved in social recognition. It is also important to acknowledge the existence of cross-reactivity between OXT and other 
neuropeptide systems such as AVP (Song and Albers, 2018), and thus the possibility that the beneficial effects of OXT treatment may have been partly mediated by AVP receptors. Thus, the molecular mechanism underlying the effects of OXT treatment on social recognition deficits following closed head injury remain a topic for further exploration.

In the present study, we did not observe an impairment in novel object recognition memory following a single closed-head injury in the 11-d-old rat, which differs from previously published data in the neonate rat (Lengel et al., 2020). This discrepancy is likely because of differences in the testing conditions; in the present study animals were tested for novel object recognition under dark conditions, in contrast to the previous study in which they were tested under normal light conditions. Dark lighting conditions were used for novel object recognition testing in the present study to maintain the consistency of testing conditions between the novel object recognition test and three-chamber test. We chose to test animals in the three-chamber test in dark conditions to avoid anxiogenic effects of excessive room lighting, which can influence the activity of animals behaving in the three-chamber test (Kaidanovich-Beilin et al., 2011).

A limitation of this study is that we did not measure changes in olfaction following TBI. Thus, we cannot rule out the possibility that the observed deficits in social novelty recognition may have been influenced by impairments in olfactory discrimination in brain-injured animals. However, the absence of deficits in sociability (stage 2) would suggest that olfaction may not be adversely affected by TBI. Moreover, a similar study reported sensory deprivation-induced social memory deficits despite normal olfaction, sociability, locomotor activity, and novel object recognition memory (Zhang et al., 2016), confirming that impairments in social behaviors can occur independent of impairments in olfaction.

Overall, these findings demonstrate that a closed head injury in 11-d-old rats results in social recognition deficits which are accompanied by alterations in neuronal functionality within the MPFC. Further, we have identified the regulation of GABAergic neurotransmission within the PFC as a potential mechanism of these effects of OXT on social behaviors. Intranasal OXT treatment has shown promise in improving social deficits in children with autism (Parker et al., 2017). To the best of our knowledge, this is the first study to demonstrate beneficial effects of OXT administration on social behavioral outcomes following TBI in pediatric animals. Our findings provide support for the potential of intranasal OXT treatment as an effective therapeutic strategy for social deficits following pediatric TBI.

\section{References}

Almazan G, Lefebvre DL, Zingg HH (1989) Ontogeny of hypothalamic vasopressin, oxytocin and somatostatin gene expression. Brain Res Dev Brain Res 45:69-75.

Andari E, Duhamel JR, Zalla T, Herbrecht E, Leboyer M, Sirigu A (2010) Promoting social behavior with oxytocin in high-functioning autism spectrum disorders. Proc Natl Acad Sci USA 107:43894394.
Anderson V, Godfrey C, Rosenfeld JV, Catroppa C (2012) 10 years outcome from childhood traumatic brain injury. Int J Dev Neurosci 30:217-224.

Bakos J, Srancikova A, Havranek T, Bacova Z (2018) Molecular mechanisms of oxytocin signaling at the synaptic connection. Neural Plast 2018:4864107.

Bicks LK, Koike H, Akbarian S, Morishita H (2015) Prefrontal cortex and social cognition in mouse and man. Front Psychol 6:1805.

Bonislawski DP, Schwarzbach EP, Cohen AS (2007) Brain injury impairs dentate gyrus inhibitory efficacy. Neurobiol Dis 25:163-169.

Brabazon F, Wilson CM, Jaiswal S, Reed J, Frey WHN, Byrnes KR (2017) Intranasal insulin treatment of an experimental model of moderate traumatic brain injury. J Cereb Blood Flow Metab 37:3203-3218.

Brizuela M, Blizzard CA, Chuckowree JA, Pitman KA, Young KM, Dickson T (2017) Mild traumatic brain injury leads to decreased inhibition and a differential response of calretinin positive interneurons in the injured cortex. J Neurotrauma 34:2504-2517.

Cantu D, Walker K, Andresen L, Taylor-Weiner A, Hampton D, Tesco G, Dulla CG (2015) Traumatic brain injury increases cortical glutamate network activity by compromising GABAergic control. Cereb Cortex 25:2306-2320.

Carron SF, Alwis DS, Rajan R (2016) Traumatic brain injury and neuronal functionality changes in sensory cortex. Front Syst Neurosci 10:47.

Carron SF, Sun M, Shultz SR, Rajan R (2020) Inhibitory neuronal changes following a mixed diffuse-focal model of traumatic brain injury. J Comp Neurol 528:175-198.

Ding MC, Wang Q, Lo EH, Stanley GB (2011) Cortical excitation and inhibition following focal traumatic brain injury. J Neurosci 31:14085-14094.

Douglas J (2020) Loss of friendship following traumatic brain injury: a model grounded in the experience of adults with severe injury. Neuropsychol Rehabil 30:1277-1302.

Faul M, Coronado V (2015) Epidemiology of traumatic brain injury. Handb Clin Neurol 127:3-13.

Gimpl G, Fahrenholz F (2001) The oxytocin receptor system: structure, function, and regulation. Physiol Rev 81:629-683.

Hanlon LA, Raghupathi R, Huh JW (2017) Differential effects of minocycline on microglial activation and neurodegeneration following closed head injury in the neonate rat. Exp Neurol 290:1-14.

Hanlon LA, Raghupathi R, Huh JW (2019) Depletion of microglia immediately following traumatic brain injury in the pediatric rat: implications for cellular and behavioral pathology. Exp Neurol 316:3951.

Hara $\mathrm{Y}$, Ago $\mathrm{Y}$, Higuchi M, Hasebe S, Nakazawa T, Hashimoto H, Matsuda T, Takuma K (2017) Oxytocin attenuates deficits in social interaction but not recognition memory in a prenatal valproic acidinduced mouse model of autism. Horm Behav 96:130-136.

Harden SW, Frazier CJ (2016) Oxytocin depolarizes fast-spiking hilar interneurons and induces GABA release onto mossy cells of the rat dentate gyrus. Hippocampus 26:1124-1139.

Harony-Nicolas H, Kay M, du Hoffmann J, Klein ME, Bozdagi-Gunal O, Riad M, Daskalakis NP, Sonar S, Castillo PE, Hof PR, Shapiro ML, Baxter MG, Wagner S, Buxbaum JD (2017) Oxytocin improves behavioral and electrophysiological deficits in a novel Shank3-deficient rat. Elife 6:e18904.

Holley SM, Galvan L, Kamdjou T, Dong A, Levine MS, Cepeda C (2019) Major contribution of somatostatin-expressing interneurons and cannabinoid receptors to increased GABA synaptic activity in the striatum of Huntington's disease mice. Front Synaptic Neurosci 11:14.

Jurek B, Neumann ID (2018) The oxytocin receptor: from intracellular signaling to behavior. Physiol Rev 98:1805-1908.

Kaidanovich-Beilin O, Lipina T, Vukobradovic I, Roder J, Woodgett JR (2011) Assessment of social interaction behaviors. J Vis Exp. Advance online publication. Retrieved Feb 25, 2011. doi: 10.3791/2473.

Kannan N, Ramaiah R, Vavilala MS (2014) Pediatric neurotrauma. Int J Crit IIIn Inj Sci 4:131-137. 
Knobloch HS, Charlet A, Hoffmann LC, Eliava M, Khrulev S, Cetin $\mathrm{AH}$, Osten P, Schwarz MK, Seeburg PH, Stoop R, Grinevich V (2012) Evoked axonal oxytocin release in the central amygdala attenuates fear response. Neuron 73:553-566.

Ko J (2017) Neuroanatomical substrates of rodent social behavior: the medial prefrontal cortex and its projection patterns. Front Neural Circuits 11:41.

Langnaese K, John R, Schweizer H, Ebmeyer U, Keilhoff G (2008) Selection of reference genes for quantitative real-time PCR in a rat asphyxial cardiac arrest model. BMC Mol Biol 9:53.

Lengel D, Huh JW, Barson JR, Raghupathi R (2020) Progesterone treatment following traumatic brain injury in the 11-day-old rat attenuates cognitive deficits and neuronal hyperexcitability in adolescence. Exp Neurol 330:113329.

Levin HS, Zhang L, Dennis M, Ewing-Cobbs L, Schachar R, Max J, Landis JA, Roberson G, Scheibel RS, Miller DL, Hunter JV (2004) Psychosocial outcome of TBI in children with unilateral frontal lesions. J Int Neuropsychol Soc 10:305-316.

Meidahl AC, Eisenried A, Klukinov M, Cao L, Tzabazis AZ, Yeomans DC (2018) Intranasal oxytocin attenuates reactive and ongoing, chronic pain in a model of mild traumatic brain injury. Headache 58:545-558.

Nakajima M, Görlich A, Heintz N (2014) Oxytocin modulates female sociosexual behavior through a specific class of prefrontal cortical interneurons. Cell 159:295-305.

Parker KJ, Oztan O, Libove RA, Sumiyoshi RD, Jackson LP, Karhson DS, Summers JE, Hinman KE, Motonaga KS, Phillips JM, Carson DS, Garner JP, Hardan AY (2017) Intranasal oxytocin treatment for social deficits and biomarkers of response in children with autism. Proc Natl Acad Sci USA 114:8119-8124.

Porterfield SP (1994) Vulnerability of the developing brain to thyroid abnormalities: environmental insults to the thyroid system. Environ Health Perspect 102:125-130.

Raghupathi R, Huh JW (2007) Diffuse brain injury in the immature rat: evidence for an age-at-injury effect on cognitive function and histopathologic damage. J Neurotrauma 24:1596-1608.

Rice D, Barone S Jr (2000) Critical periods of vulnerability for the developing nervous system: evidence from humans and animal models. Environ Health Perspect 108:511-533.

Rosema S, Crowe L, Anderson V (2012) Social function in children and adolescents after traumatic brain injury: a systematic review 1989-2011. J Neurotrauma 29:1277-1291.

Ryan NP, Anderson V, Godfrey C, Beauchamp MH, Coleman L, Eren S, Rosema S, Taylor K, Catroppa C (2014) Predictors of very-longterm sociocognitive function after pediatric traumatic brain injury: evidence for the vulnerability of the immature "social brain." J Neurotrauma 31:649-657.

Ryan NP, Catroppa C, Godfrey C, Noble-Haeusslein LJ, Shultz SR, O'Brien TJ, Anderson V, Semple BD (2016) Social dysfunction after pediatric traumatic brain injury: a translational perspective. Neurosci Biobehav Rev 64:196-214.

Sala M, Braida D, Lentini D, Busnelli M, Bulgheroni E, Capurro V, Finardi A, Donzelli A, Pattini L, Rubino T, Parolaro D, Nishimori K, Parenti M, Chini B (2011) Pharmacologic rescue of impaired cognitive flexibility, social deficits, increased aggression, and seizure susceptibility in oxytocin receptor null mice: a neurobehavioral model of autism. Biol Psychiatry 69:875-882.
Semple BD, Canchola SA, Noble-Haeusslein LJ (2012) Deficits in social behavior emerge during development after pediatric traumatic brain injury in mice. J Neurotrauma 29:2672-2683.

Semple BD, Dixit S, Shultz SR, Boon WC, O'Brien TJ (2017) Sex-dependent changes in neuronal morphology and psychosocial behaviors after pediatric brain injury. Behav Brain Res 319:48-62.

Song Z, Albers HE (2018) Cross-talk among oxytocin and argininevasopressin receptors: relevance for basic and clinical studies of the brain and periphery. Front Neuroendocrinol 51:14-24.

Swijsen A, Nelissen K, Janssen D, Rigo JM, Hoogland G (2012) Validation of reference genes for quantitative real-time PCR studies in the dentate gyrus after experimental febrile seizures. BMC Res Notes 5:685.

Timaru-Kast R, Herbig EL, Luh C, Engelhard K, Thal SC (2015) Influence of age on cerebral housekeeping gene expression for normalization of quantitative polymerase chain reaction after acute brain injury in mice. J Neurotrauma 32:1777-1788.

Tops M, Huffmeijer R, Linting M, Grewen KM, Light KC, Koole SL, Bakermans-Kranenburg MJ, van ljzendoorn MH (2013) The role of oxytocin in familiarization-habituation responses to social novelty. Front Psychol 4:761.

Urban-Ciecko J, Barth AL (2016) Somatostatin-expressing neurons in cortical networks. Nat Rev Neurosci 17:401-409.

Wei ZZ, Lee JH, Zhang Y, Zhu YB, Deveau TC, Gu X, Winter MM, Li J, Wei L, Yu SP (2016) Intracranial transplantation of hypoxia-preconditioned iPSC-derived neural progenitor cells alleviates neuropsychiatric defects after traumatic brain injury in juvenile rats. Cell Transplant 25:797-809.

Witgen BM, Lifshitz J, Smith ML, Schwarzbach E, Liang SL, Grady MS, Cohen AS (2005) Regional hippocampal alteration associated with cognitive deficit following experimental brain injury: a systems, network and cellular evaluation. Neuroscience 133:1-15.

Witkowski ED, Gao Y, Gavsyuk AF, Maor I, DeWalt GJ, Eldred WD, Mizrahi A, Davison IG (2019) Rapid changes in synaptic strength after mild traumatic brain injury. Front Cell Neurosci 13:166.

Wrobel LJ, Reymond-Marron I, Dupré A, Raggenbass M (2010) Oxytocin and vasopressin enhance synaptic transmission in the hypoglossal motor nucleus of young rats by acting on distinct receptor types. Neuroscience 165:723-735.

Yager JY, Thornhill JA (1997) The effect of age on susceptibility to hypoxic-ischemic brain damage. Neurosci Biobehav Rev 21:167174.

Yizhar O, Fenno LE, Prigge M, Schneider F, Davidson TJ, O'Shea DJ, Sohal VS, Goshen I, Finkelstein J, Paz JT, Stehfest K, Fudim R, Ramakrishnan C, Huguenard JR, Hegemann P, Deisseroth $\mathrm{K}$ (2011) Neocortical excitation/inhibition balance in information processing and social dysfunction. Nature 477:171-178.

Zamani A, Ryan NP, Wright DK, Caeyenberghs K, Semple BD (2020) The impact of traumatic injury to the immature human brain: a scoping review with insights from advanced structural neuroimaging. J Neurotrauma 37:724-738.

Zhang JB, Chen L, Lv ZM, Niu XY, Shao CC, Zhang C, Pruski M, Huang Y, Qi CC, Song NN, Lang B, Ding YQ (2016) Oxytocin is implicated in social memory deficits induced by early sensory deprivation in mice. Mol Brain 9:98. 